\title{
Collagenous colitis: a distinctive and potentially reversible disorder
}

\author{
AS PIETERSE, * R HECKER, $\dagger$ R ROWLAND* \\ From the *Division of Tissue Pathology, Institute of Medical and Veterinary Science, and the \\ $\uparrow$ Gastroenterology Unit, Royal Adelaide Hospital, Adelaide, South Australia
}

SUMMARY A case of collagenous colitis is reported. The patient's symptoms cleared up after a course of mepacrine hydrochloride. Biopsies taken after clinical recovery still showed some increase in the number of reticulin fibres present in the upper layers of the lamina propria but the dense collagenous band previously noted was no longer present and has not recurred during the subsequent six years.

Collagenous colitis appears to be a distinctive disorder and only three cases have been recorded previously. ${ }^{1-3}$ The reported cases have presented clinically with chronic watery diarrhoea and histopathologically, the characteristic feature is a thick subepithelial collagenous band.

This paper reports a case of collagenous colitis in which the collagenous band largely resolved and the patient's diarrhoea stopped after a course of mepacrine hydrochloride.

\section{Case report}

A 62-year-old woman presented in August 1973 with a two-week history of diarrhoea. She was having up to 12 watery bowel motions daily with urgency but, apart from a three-day history of pain in the right iliac fossa, she had no other gastrointestinal tract complaints. She was obese, but physical examination revealed no other abnormality and her blood pressure was $140 / 80 \mathrm{~mm} \mathrm{Hg}$. On sigmoidoscopy the rectal mucosa was congested and was covered by excessive quantities of mucus. No pathogens were found in the faeces on microscopy or culture. Barium enema and barium meal studies were normal. Her diarrhoea persisted despite treatment with codeine phosphate, amitriptyline, tiemonium iodine, dicyclomine, kaolin and opium mixture and lomotil. Repeat sigmoidoscopy with mucosal biopsy was performed in January 1974. The histology of the rectal mucosa showed a subepithelial collagenous band measuring up to $60 \mu \mathrm{m}$ in thickness. This band stained positively for collagen with Masson's trichrome and Sirius Red

Accepted for publication 6 July 1981
(Fig. 1). The Congo red stain for amyloid was negative. The mucosal crypts were regular and the lamina propria contained slightly increased numbers of mononuclear cells, including quite numerous plasma cells. The muscularis mucosae was normal. The submucosal vessels were normal.

She was given a course of metronidazole $200 \mathrm{mg}$ tds for seven days and her diarrhoea improved temporarily but she was readmitted weak and unwell in February 1974. A three-day faecal fat collection contained only $8 \mathrm{~g}$ of fat and jejunal biopsy was normal. In May 1974 her diarrhoea worsened and on sigmoidoscopy the rectal mucosa was congested and there were pinpoint areas of haemorrhage present. Biopsy was repeated and a diagnosis of collagenous colitis was confirmed. She was then given a course of mepacrine ( $100 \mathrm{mg}$ tds) for 10 days. After this her diarrhoea ceased and her bowel motions became normal. Sigmoidoscopy in July 1974 was normal and histology of the biopsy showed that the collagenous band previously observed had disappeared (Fig. 2). In mid-1978, she developed diarrhoea after a holiday overseas. In 1979 she again developed diarrhoea but Salmonella adelaide was cultured from her stool. She improved slowly after taking a seven-day course of ampicillin $500 \mathrm{mg}$ six hourly. All the patient's biopsies were compared with controls. The controls consisted of 10 appropriately stained rectal biopsies which had previously been reported as histologically normal. In each of the follow-up rectal biopsies the collagen band was absent and the number of lamina propria round cells appeared to be present in normal numbers. Although the distinctive collagen band disappeared, compared with the control biopsies the post-treatment rectal biopsies showed a 


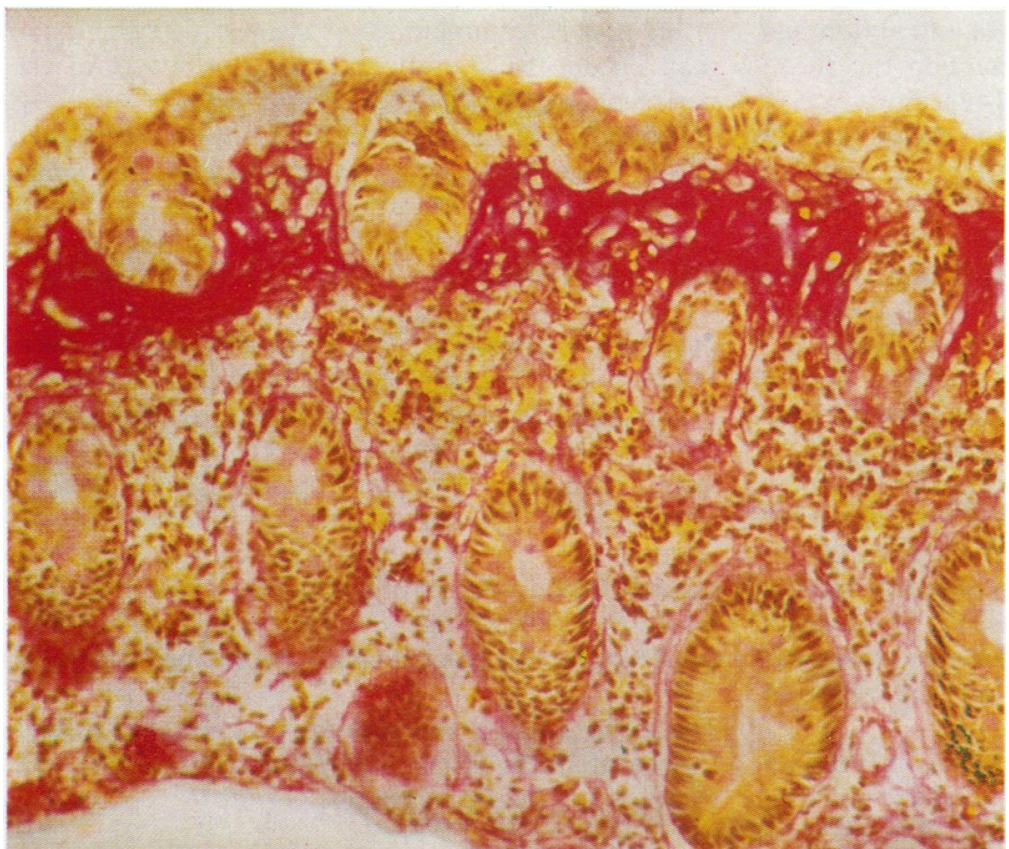

Fig. 1 Large bowel mucosa with thick abnormal submucosal collagenous band. Sirius Red $\times 250$.

Fig.1

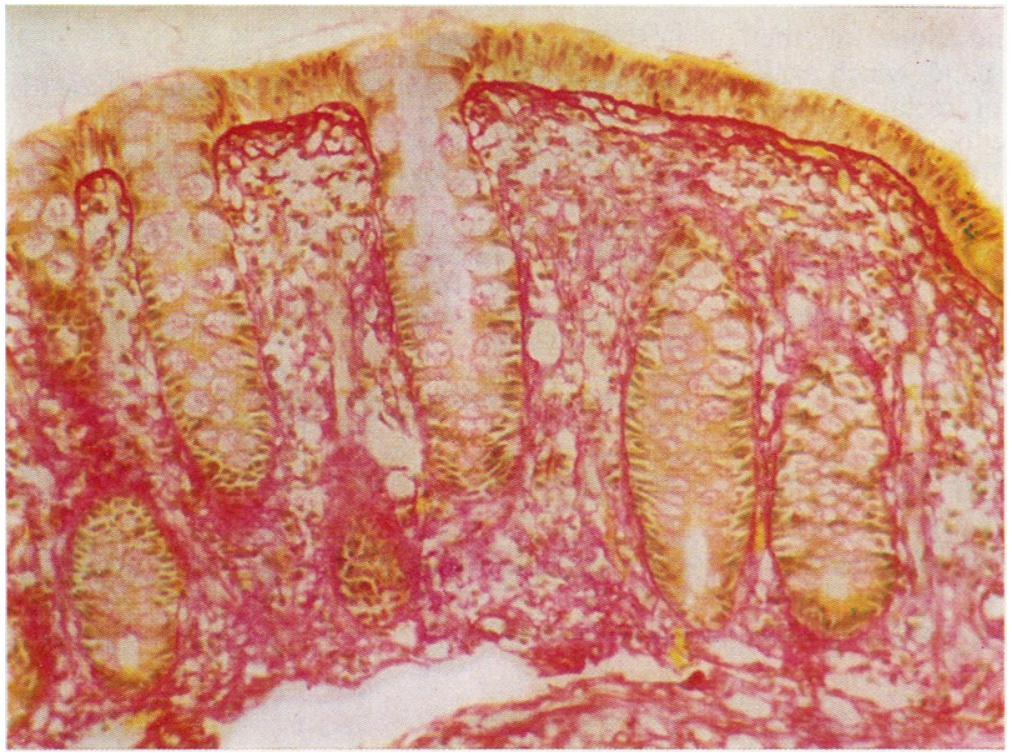

Fig. 2 Large bowel mucosa with normal architecture and no abnormal collagenous band. Sirius Red $\times 250$.

Fig.2

slight but definite increase in the amount of connective tissue in the superficial lamina propria.

In June 1980 when she had a radical mastectomy for carcinoma her only gastrointestinal complaint was occasional looseness of bowel motions.

\section{Discussion}

The duration of symptoms in our patient and the three previously reported cases ${ }^{1-3}$ has ranged from two weeks to 96 months. All of the reported patients 
have complained of watery diarrhoea and abdominal pain. In one case mucus was present in the stool ${ }^{2}$ but none of the patients had rectal bleeding.

The endoscopic appearance of the rectal mucosa in collagenous colitis varies. It may be normal, oedematous, congested or friable and show contact bleeding. Barium enema is normal and it is only after histological examination of the rectal mucosa that the diagnosis of collagenous colitis becomes evident.

The striking and distinctive abnormality of the large bowel mucosa is the thick subepithelial collagenous band. This band has measured up to $60 \mu \mathrm{m}$ in thickness which is 10 times the thickness of the basement membrane of control patients. ${ }^{3}$ The staining reactions of the band indicate that it consists of collagen. Electron microscopy studies have shown that the band consists of collagen fibres closely associated with thickened basement membrane. ${ }^{13}$ Amyloid stains in all the reported cases have been negative.

The principal interest of this case lies in the fact that the patient's diarrhoea stopped and the mucosal lesion partially recovered after a course of mepacrine. The disappearance of the band is not the result of a sampling error, as multiple biopsies have been taken since her diarrhoea stopped, and none of the fragments show the collagenous band which was present in all of the fragments of rectal mucosa taken at the initial two separate biopsy sessions done during the 10 months that she was symptomatic.

Although the distinctive dense collagen band disappeared compared with normal control rectal biopsies there is a slight excess in the amount of collagen in the lamina propria. During the subsequent years there was no progressive increase in the amount of collagen and the collagen band did not reappear.

The aetiology of this disorder is unknown but the increase in the lamina propria round cells and the response to mepacrine are suggestive of an underlying infectious agent. Lindström originally suggested that the diarrhoea was due to the collagenous band interfering with water absorption. Both Nielsen et $a l^{2}$ and Bogomoletz et $a l^{3}$ suggest that the lesion may be due to alteration in the fibroblasts of the pericrypt sheath. 4

A similar collagenous band has not been described in the large bowel in systemic sclerosis, the other connective tissue disorders, ulcerative colitis or Crohn's disease. Jejunal biopsy was normal in this case and Lindström's case, a finding which distinguishes collagenous colitis from collagenous sprue ${ }^{5}$ in which the abnormality is in the small bowel. Mepacrine hydrochloride was used as an antimalarial drug during the Second World War. Today mepacrine is little used but it has been shown to be of value in treatment of tapeworm and Giardia lamblia infestations. ${ }^{6}$ No tapeworms or Giardia lamblia were isolated from this case. It is not possible to say what role the course of mepacrine played in the resolution of the collagenous band in this case but clinical recovery did coincide with mepacrine treatment.

The authors wish to thank Jenny Wagner and Carmen Liyanaratchi for typing the manuscript, and Shevill Mathers for the photographs.

\section{References}

${ }^{1}$ Lindström CG. Collagenous colitis with watery diarrhoea -a new entity? Path Europ 1976;11:87-9.

${ }^{2}$ Nielsen VT, Vetner M, Harslof E. Collagenous colitis. Histopathology 1980;4:83-6.

${ }^{3}$ Bogomoletz WV, Adnet JJ, Birembaut P, Feydy P, DuPont P. Collagenous colitis: an unrecognised entity. Gut 1980;21:164-8.

4 Pascal RR, Kage IG, Lone N. Colonic pericryptal fibroblast sheath. Replication, migration, and cytodifferentiation of a mesenchymal cell system in adult tissue. Gastroenterology 1968;54:835-51 and Gastroenterology $1968 ; 54: 852-65$.

${ }^{5}$ Weistein WM, Saunders DR, Tydgat GN, Rubin CE. Collagenous sprue: an unrecognised type of malabsorption. N Engl J Med 1970;283:1297-1301.

- Goodman LS, Gilman A. The pharmacological basis of therapeutics, 5th ed. London: Macmillan, 1975.

Requests for reprints to: Dr S Pieterse, Division of Tissue Pathology, Institute of Medical and Veterinary Science, Box 14 Rundle Street Post Office, Adelaide, South Australia 5000. 